\title{
PARTIAL DISCHARGE INCEPTION VOLTAGE CHANGE IN LOW VOLTAGE ELECTRIC MOTORS CASE STUDY: HIGH DC CURRENT EXCITATION EFFECT
}

\author{
Nezih Ozcelik, Emel Onal \\ Istanbul Technical University, Electrical Engineering Dep. Maslak, Istanbul, Turkey \\ e-mail:ozceliknezih@gmail.com, eonal@itu.edu.tr
}

\begin{abstract}
The paper is about partial discharge inception voltage on low voltage electrical motors. In industry partial discharge inception voltage (PDIV) tests are commonly used in quality control of insulation systems and to guarantee the reliable working condition of serial production goods. The main study area on paper is high DC current excitation effect on motor windings. Firstly, PDIV values are obtained by using PDIV testers which use in industry and then high DC current is applied to one of the motor windings. After these steps, PDIV of motor windings are measured again. Results which are obtained before the $D C$ current excitation and after the $D C$ current excitation are compared to each other. According to the results radical change in partial discharge inception voltage are seen on one of the motor winding which subjected to the high DC current excitation.
\end{abstract}

Keywords: Partial Discharge Inception Voltage, Low Voltage Electric Motors, Direct Current Excitation, Partial Discharge Inception Voltage Testing, Motor Driver.

\section{INTRODUCTION}

When we look at the industry, there are different motor types. Some of these motors can operate directly from the main power line but some of them need a driver unit for its own working principle. This driver unit includes a converter and inverter unit. Converter unit which converts $A C$ voltage level to $D C$ voltage level and also inverter unit convert the $D C$ voltage level to $A C$ voltage level. The main function of motor controller is adjusting speed level of motor. Up to the application in industry, controlling the speed level can be critical. Especially fan, pump and conveyor type applications need adjusted speed control. Adjustable speed drives are critical for motor manufacturers because of insulation capabilities. The main effect on motors is repeated impulse voltage effects on motor windings. Pulse Width Modulation is one of the most common effects on low voltage motor applications. Partial Discharge Inception Voltage measurement becomes important to measure quality of insulation system. There are lots of application areas about partial discharge inception voltage and also for motors. IEC 60034-18-41 standard is applicable for rotating electrical machines. This standard are deal with the Type I insulation systems which are generally applied to the rotating electrical machines rated $700 \mathrm{~V}$ rms or less and tend to have random wound windings. The main concept about this standard is qualification of the insulation system and also, routine tests of the complete windings of the service machines. But, this standard does not apply to the rotating machines which are only started by converters, rotating electrical machines with rated voltage $<300 \mathrm{~V}$ rms and rotor windings of rotating electrical machines operating at $<200 \mathrm{~V}$ peak value. General failure modes and their statistics are given at Figure 1. 


\section{IRITIE}

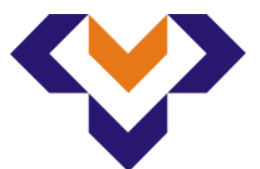

Ipplied Reserer rhes in Technics, Technologies and Bduration Journal of the Faculty of Technics and Technologies, Trakia University https://sites.google.com/a/trakia-uni.bg/artte/

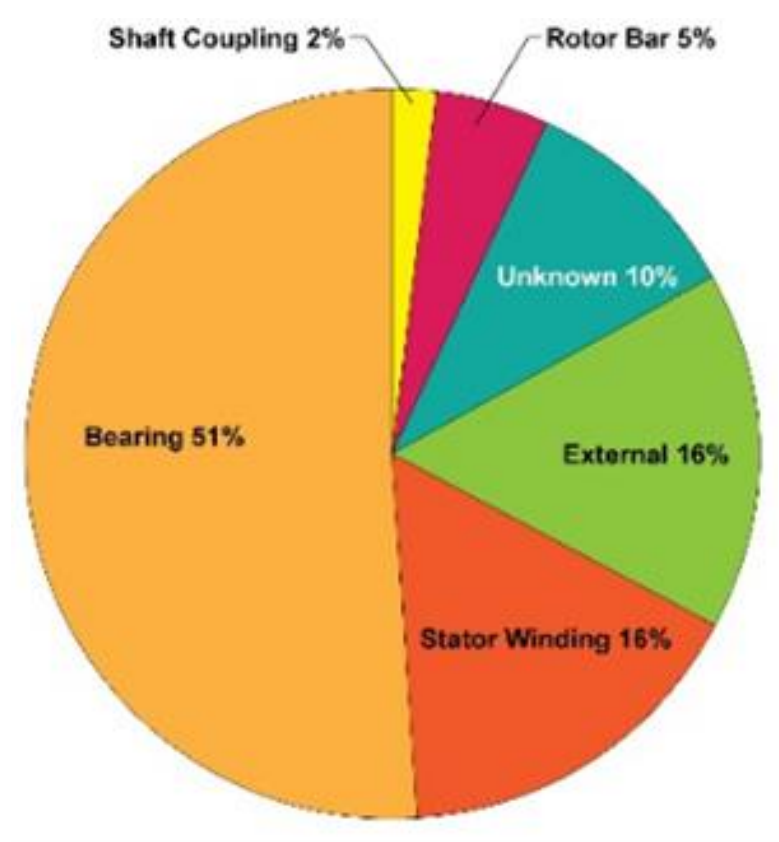

Figure 1. Main failure modes and their percentages on whole motor failure distribution [1]

\section{THE CAUSES OF PARTIAL DISCHARGE AT MOTORS}

According to the IEC 60034-18-41 partial discharge inception voltage can be defined as lowest voltage at which partial discharge are initiated in the test arrangement when the voltage applied to the test object is gradually increased from a lower value at which no such discharges are observed. In practice, many of the aforementioned insulation ranges are shown below.
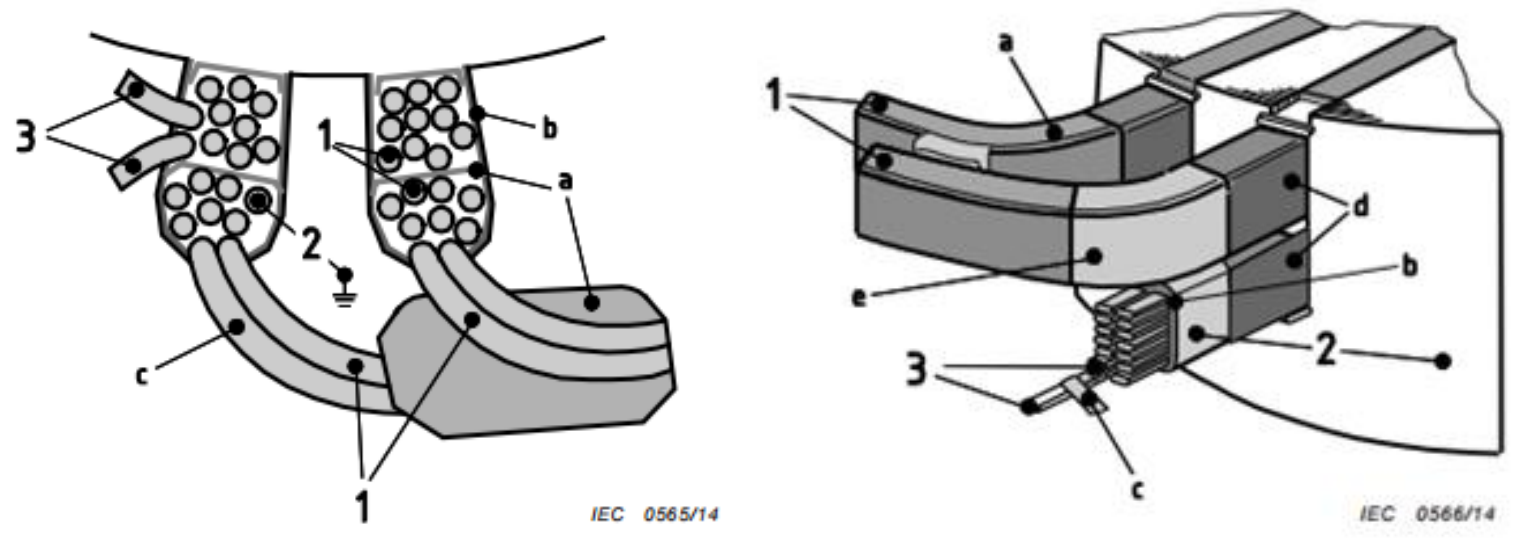
a phase insulation / overhang insulation
b main wall insulation
c turn insulation
d slot corona protection
e overhang corona protection (stress grading)

Figure 2. Example of a random wound design and form-wound design 


\section{IRTITE

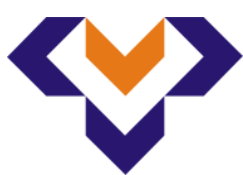 \\ Ipplied Resseirlores in Technics, Technologies and Educration \\ Journal of the Faculty of Technics and Technologies, Trakia University https://sites.google.com/a/trakia-uni.bg/artte/}

The main winding types can be classified into two types. First one is the subject to impulse voltage but the winding will not be exposed to Partial Discharge (PD) over its expected life (type I). The second one subjected to repeated impulse voltages where PD may occur in operation (type II). But there are three duty levels for motor insulation systems. A type signs the benign, $B$ type can be defined as medium and $C$ type can also severe. [2]

For every type of windings which are experienced short rise time voltage impulses of significant magnitude, high voltage stresses will be created many areas.

These areas are listed as between conductors in different phases, between a conductor and ground and between adjacent turns in the line-end coil as shown fig. 2 .

Today especially in serial production, defects can be determined with the help of test systems. These defects can be classified into three main divisions. These defects are listed below and some of them are shown in figure 3.

1- Wire in the wrong place: wire out of the slot, incorrect path of the winding, reduced distance between windings or in respect to the grounded frame.

2- Parts assemble incorrectly: no insulation sheet in the slot, no or misplaced insulating ribbons, general misplacement or defective insulating parts.

3- Defects in the construction materials: wire enamel too thin, porous or cracked enamel, moisture content in dielectric parts, reduced dielectric strength of the raw material (impurities, process, etc.) [3]

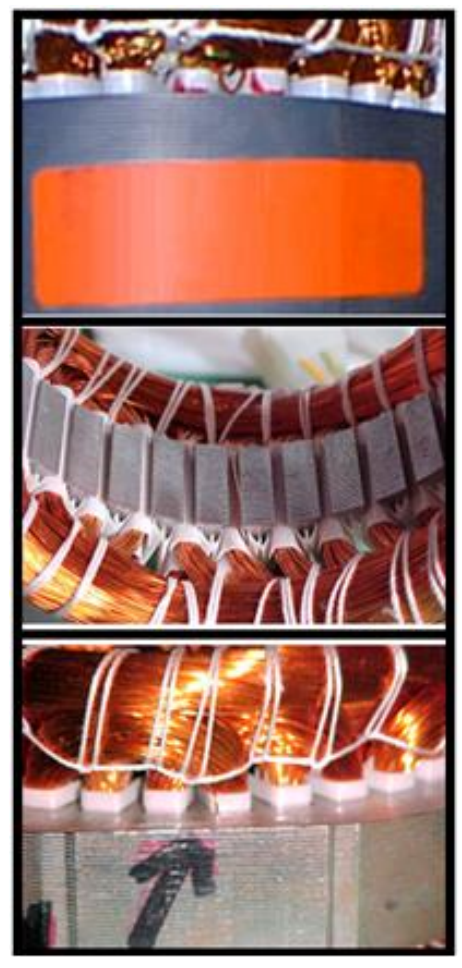

Figure 3. a: misplaced wire over the stator; b: turn out of the slot and in contact ground; $c$ : turn contact with ground [2]

The measurement technique detects by stressing the sensitivity of high voltage tests, the low-energy phenomena that are well in advance of true dielectric breakdown or resistance lowering and are strictly related to geometrical factors as well as to dielectric performance of the insulation. [4] 


\section{EXPERIMENTAL RESULTS OF PARTIAL DISCHARGE INCEPTION VOLTAGE OF ELECTRICAL MOTORS}

In this section partial discharge inception voltage tests are conducted to three phase induction motors. Electric motors convert electrical energy to mechanical energy. Induction motors are the mostly used electrical motors in whole motor family. It combines several advantages. These advantages can be listed as: Simplicity of operation, robustness, low cost and they can be combined with frequency converter. In this case study, high DC current applied to the motor windings. Before the excitation, all motors and their all phases are measured for the view of partial discharge inception voltage (PDIV). After the high DC current excitation to the windings partial discharge inception voltage performance of motor measured again. For all phases partial discharge inception voltage of each motor compared separately in table 1 and 2 for five electric motors.

Table 1. Comparative partial discharge inception voltage test results before and after high current dc excitation

\begin{tabular}{|c|c|c|c|c|}
\hline & $m$ & Phase 1-2 & Phase 1-3 & Phase 2-3 \\
\hline \multirow{5}{*}{$\begin{array}{l}\text { PDIV Test Before } \\
\text { DC Voltage } \\
\text { Excitation to } \\
\text { windings }\end{array}$} & Electric Motor 1 & 2021 & 2296 & 2127 \\
\hline & Electric Motor 2 & 1935 & 2408 & 1820 \\
\hline & Electric Motor 3 & 2046 & 2112 & 1927 \\
\hline & Electric Motor 4 & 2004 & 2301 & 1987 \\
\hline & Electric Motor 5 & 1980 & 2089 & 2102 \\
\hline \multirow{5}{*}{$\begin{array}{l}\text { PDIV Test After } \\
\text { DC Voltage } \\
\text { Excitation to } \\
\text { windings }\end{array}$} & Electric Motor 1 & 1339 & 1616 & 1324 \\
\hline & Electric Motor 2 & 1773 & 2005 & 1326 \\
\hline & Electric Motor 3 & 1656 & 1506 & 1416 \\
\hline & Electric Motor 4 & 1767 & 1813 & 1319 \\
\hline & Electric Motor 5 & 1662 & 1710 & 2025 \\
\hline
\end{tabular}

Table 2. Comparative partial discharge decrease with dc current excitation in terms of percentage

\begin{tabular}{|l|r|r|r|}
\hline \multicolumn{3}{|c|}{ PDIV Decrease with DC Current in terms of Percentage } \\
\cline { 2 - 4 } & Phase 1-2 Phase 1-3 & Phase 2-3 \\
\hline Electric Motor 1 & 33,75 & 29,62 & 37,75 \\
\hline Electric Motor 2 & 8,37 & 16,74 & 27,14 \\
\hline Electric Motor 3 & 19,06 & 28,69 & 26,52 \\
\hline Electric Motor 4 & 11,83 & 21,21 & 33,62 \\
\hline Electric Motor 5 & 16,06 & 18,14 & 3,66 \\
\hline
\end{tabular}

Table 2 gives the decrease on phase winding PDIV results. Compared to the to others Electric Motor 1 and Phase 2-3 has the biggest decrease on partial discharge inception voltage. The value belongs to this pair nearly $37.75 \%$ decrease on PDIV. Moreover results are given for each motor separately in figure 4. 


\section{IRTIE}

Ipplied Researrches in Technics, Technologies ind Bducition

Journal of the Faculty of Technics and Technologies, Trakia University https://sites.google.com/a/trakia-uni.bg/artte/
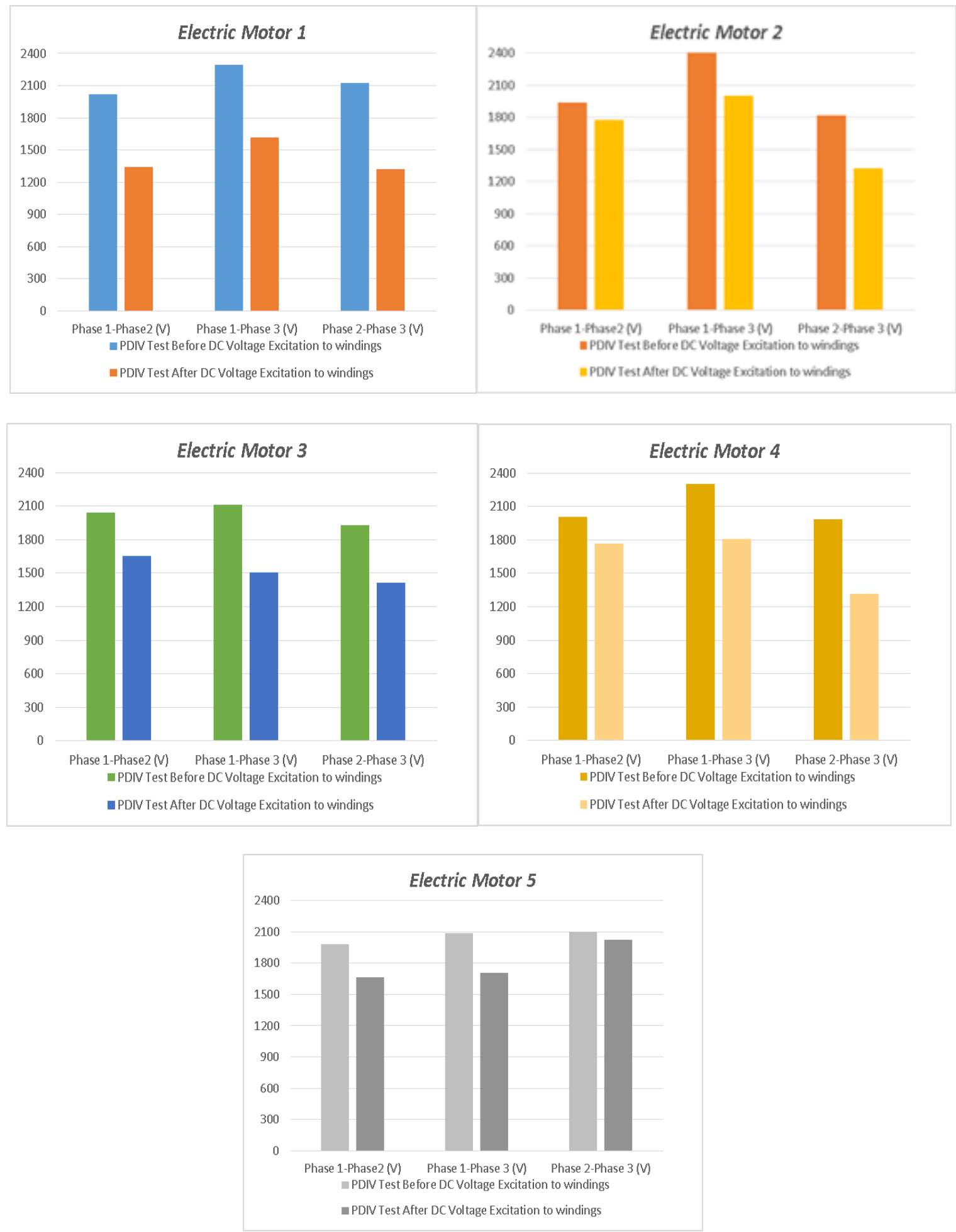

Figure 4. High DC voltage effect comparison on windings by using partial discharge inception voltage test on five different electric motors

IRTIIE Vol. 5, No. 3, 2017 ISSN 1314-8788 (print), ISSN 1314-8796 (online), doi: 10.15547/artte.2017.03.007 


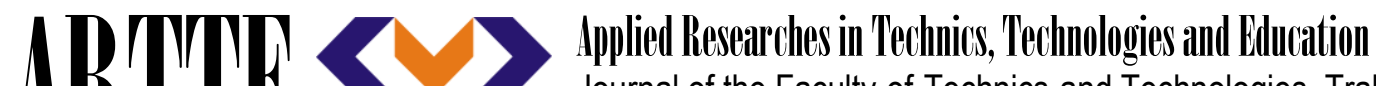 Journal of the Faculty of Technics and Technologies, Trakia University https://sites.google.com/a/trakia-uni.bg/artte/}

\section{CONCLUSION}

As a conclusion, in this case study, the effect of high DC current on motor windings is analyzed deeply. In this research, firstly partial discharge inception voltage withstand of 5 electric motors are obtained by using PDIV tester which use in industry commonly. After the measurement, high DC current is injected to the 3 phase electric motor windings. To understand the effect of high DC current, PDIV values are measured again. Comparative study is conducted for the conditions before and after the excitations. As a result, a sharp decrease in partial inception voltage on motor windings can be seen after DC excitation.

\section{REFERENCES}

[1] Thorsen O.V., Dalva M. (1995). A survey of faults on induction motors in offshore oil industry, petrochemical industry, gas terminals and oil refineries. IEEE Transactions on Industry Applications, Vol. 31, No. 5, (1995), pp. 1186-1196. DOI: 10.1109/28.464536

[2] Bogh D., Coffee J., Stone G., Custodio J. (2004). Partial discharge inception testing on low voltage motors. Petroleum and Chemical Industry Technical Conference, Fifty-First Annual Conference 2004. DOI: 10.1109/PCICON.2004.1352807.

[3] Electrical Dynamic Company, "The partial discharge method for the detection of hidden defects in windings and subassemblies and the reliability evaluation for the use with solidstate drivers," Technical Note.

[4] IEC 60034-18-41, Rotating electrical machines - Part 18-41: partial discharge free electrical insulation systems (Type I) used in rotating electrical machines fed from voltage converters-qualification and quality control tests, 2014.

[5] WEG, "Specifications of electric motors", Application note, 2014. 